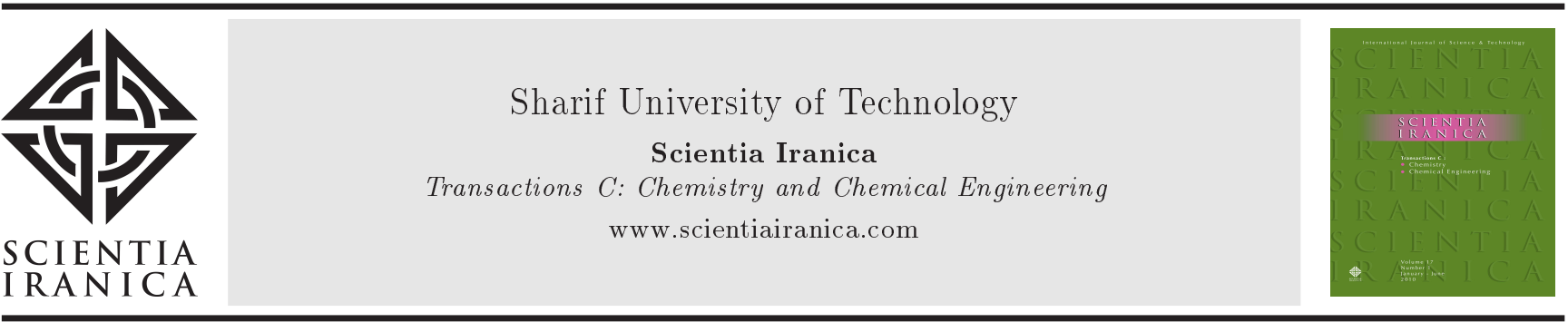

\title{
Development of Li-doped cubic P mesoporous silica MCM-48 as a novel humidity sensor
}

\author{
M. Anbia ${ }^{a, *}$ and S. Kadkhodazade ${ }^{b}$ \\ a. Research Laboratory of Nanoporous Materials, Faculty of Chemistry, Iran University of Science and Technology, Tehran, P.O. \\ Box 16846-13114, Iran. \\ b. Research Laboratory of Advanced Materials, Chemistry and Chemical Engineering Research Center of Iran, Tehran, P.O. Box \\ 14335-186, Iran.
}

Received 6 November 2013; received in revised form 23 October 2014; accepted 4 January 2016

\section{KEYWORDS}

$\mathrm{SiO}_{2}$

Sensors;

$\mathrm{LiCl}$;

Impedance;

Porosity.

\begin{abstract}
LiCl-doped mesoporous silica MCM-48 with cubic mesostructure, using a different doping concentration of $\mathrm{LiCl}$, has been prepared. The LiCl-MCM-48 type materials were characterized employing XRD, FT-IR, SEM, and nitrogen adsorptiondesorption isotherm. We had the humidity sensors on a ceramic substrate with two Ag-Pd interdigital electrodes with five fingers. The sample with $15 \mathrm{wt} \% \mathrm{LiCl}$-doped MCM-48 shows an excellent linearity in the whole humidity range of $11 \%-97 \%$. It has very good response and recovery time, about 22 and $30 \mathrm{sec}$, respectively.
\end{abstract}

(C) 2016 Sharif University of Technology. All rights reserved.

\section{Introduction}

Humidity sensors have gained increasing applications in industrial processing and environmental control [1]. Many scientific and technological efforts have been made to improve the overall properties of humidity sensors in terms of wide operation range of temperature, high sensitivity and selectivity towards water, short response time, small hysteresis loop, easy processing, and reproducibility [2].

The humidity sensors are relative humidity sensors, which can be classified as ceramic, semiconductor, and polymer humidity sensors [3]. Commercial ceramic humidity sensors have good properties such as thermal and chemical stability, wide range of working temperature, and environmental adaptability, but they are usually needed to be heated up in order to wash out moisture $[3,4]$.

However, the sensing characteristics (e.g. response time, recovery time, reproducibility, stability, and lin-

\footnotetext{
*. Corresponding author.

Email address: anbia@iust.ac.ir (M. Anbia)
}

earity) of ceramic sensors still need to be improved [5$7]$.

In recent years, Mesoporous silicates with variable pore structures and large specific surface and pore volume have been extensively investigated to achieve high humidity sensitivity as well as potential appropriateness for humidity sensors [8]. As an adsorbent, catalyst [9], catalyst support, and the template for the synthesis of advanced nanostructures [10-12], MCM-48 may be a more potent candidate than MCM-41. Compared to 2D hexagonal MCM-41 in the M41S family, MCM-48 mesoporous silicas with 3-Dimensional (3D) cubic $I a \overline{3} d$ mesostructure have interesting mesostructure which consists of two interpenetrating continuous networks of chiral channels [13-16]. Therefore, it is expected that this unique $3 \mathrm{D}$ mesoporous structure could provide more favorable mass transfer, facilitating $\mathrm{H}_{2} \mathrm{O}$ motion without pore blocking. $\mathrm{H}_{2} \mathrm{O}$ molecules loaded into $3 \mathrm{D}$ cubic pore systems have more chances for escaping from mesopore. Within our study, although MCM48 possessed larger particle size than MCM-41, the motion rate of $\mathrm{H}_{2} \mathrm{O}$ from MCM-48 was obviously faster than that from MCM-41, further demonstrating the 
advantage of the 3D interconnected pore networks of MCM-48.

Like other humidity sensing ceramics, based on proton-conducting mechanism, doping with alkali ions facilitates formation of hydrated protons [17]. The humidity sensitivity of MCM-48 can be enhanced by adding electrolyte dopants, e.g. LiCl. Modification of the MCM-48 material using hydrophilic $\mathrm{Li}^{+}$resulted in change in impendence, causing it to be considerably greater than that of the undoped MCM-48. This change was attributed to the potential of the $\mathrm{Li}^{+}$to dissociate into the adsorbed water, increasing conductivity of the water layers $[18,19]$. Complex impedance plots indicate the involvement of protons at low Relative Humidity $(\mathrm{RH})$ values while $\mathrm{Li}^{+}$becomes dominant at higher $\mathrm{RH}$ values.

In this work, $\mathrm{LiCl}$ was used as a dopant to the mesoporous silica MCM-48 to improve the sensitivity. Humidity sensing properties of LiCl-doped MCM$48(X)$ are reported in comparison with those of pure MCM-48 (where $X$ is the mass fraction of $\mathrm{LiCl}$ in $1 \mathrm{~g}$ of MCM-48). It is found that the addition of $\mathrm{LiCl}$ is very beneficial in the improvement of humidity sensing features.

\section{Experimental}

\subsection{Preparation of materials}

Mesoporous silica MCM-48 was synthesized under hydrothermal conditions. The surfactant, Cetyltrimethy Lammonium Bromide (CTAB), and sodium hydroxide $(\mathrm{NaOH})$ were dissolved in distilled water under stirring at $323 \mathrm{~K}$. The silica source, tetraethyl orthosilicate (TEOS), was added to the abovementioned mixture under stirring. The molar composition of the synthesized mixture was $\mathrm{SiO}_{2}: 0.5 \mathrm{NaOH}: 0.5 \mathrm{CTAB}: 55 \mathrm{H}_{2} \mathrm{O}$. After stirring for $3 \mathrm{~h}$, the synthetic mixture was transferred to a Teflon-lined autoclave and heated at $405 \mathrm{~K}$ for $40 \mathrm{~h}$. After the autoclave was cooled to room temperature, the produced solid was filtered and washed repeatedly with distilled water, dried at $353 \mathrm{~K}$ for $12 \mathrm{~h}$, and then calcined in air at $813 \mathrm{~K}$ for $6 \mathrm{~h}$; then, the MCM-48 product was obtained. Firstly, varying amounts of $\mathrm{LiCl}(0,0.05,0.1,0.15,0.2 \mathrm{~g})$ were dissolved in $10 \mathrm{ml}$ of ethanol in five beakers. Then, $1 \mathrm{~g}$ of MCM-48 was soaked in each beaker and ultrasonically oscillated for $2 \mathrm{~h}$. They were placed in a vacuum oven at $333 \mathrm{~K}$ for $20 \mathrm{~h}$ to be dried.

\subsection{Fabrication and measurement of sensors}

LiCl-MCM-48 $(X)$ powder and ethyl cellulose (protective layer) were mixed with isopropanol in a weight ratio of 5:1:100 to form a dilute paste. The paste was screen-printed on a ceramic substrate $(6 \mathrm{~mm}, 3 \mathrm{~mm}$ and $0.5 \mathrm{~mm}$ ) with five pairs of $\mathrm{Ag}-\mathrm{Pd}$ interdigital electrodes (width and distance of electrodes: $0.2 \mathrm{~mm}$ )

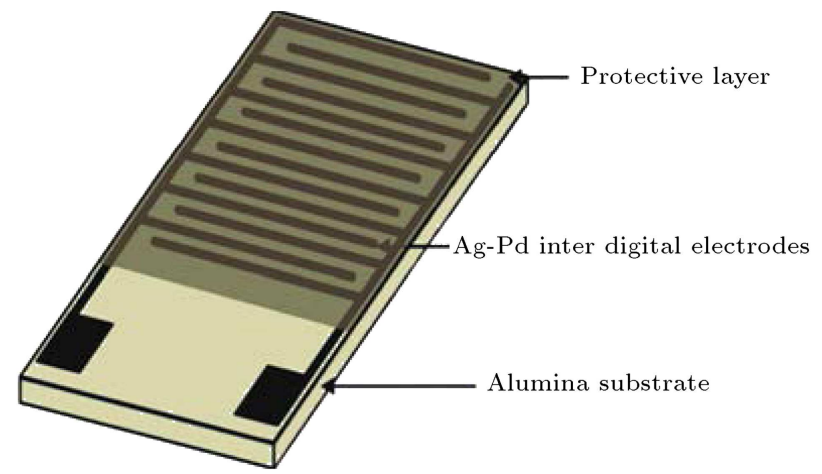

Figure 1. A schematic diagram of the humidity sensor.

to form a film with a thickness of about $20 \mu \mathrm{m}$, and then, the film was dried in vacuum oven at $80^{\circ} \mathrm{C}$ for $5 \mathrm{~h}$. Finally, the humidity sensor was obtained after aging at $\mathrm{RH}$ of $97 \%$ and a voltage of $1 \mathrm{~V}$ and $100 \mathrm{~Hz}$ for $24 \mathrm{~h}$. Figure 1 shows the structure of the sensor. Characteristic curves of humidity sensing were measured on a 821 model LCR analyzer (LCR analyzer is a piece of electronic test equipment used to measure the inductance $(L)$, capacitance $(C)$, and resistance $(R)$ of a component) [20] (Made in Taiwan) at room temperature. The controlled humidity environments with supersaturation aqueous solutions of different salts of $\mathrm{LiCl}, \mathrm{MgCl}_{2}, \mathrm{~K}_{2} \mathrm{CO}_{3}, \mathrm{NaBr}, \mathrm{KCl}, \mathrm{SrCl}_{2}$, and $\mathrm{K}_{2} \mathrm{SO}_{4}$, at room temperature, yielded 11, 33, 43, 57, 71,84 , and $97 \%$ relative humidity, respectively.

\subsection{Method of characterization}

LCR meter was used to measure the humidity sensitivity characteristic curves for the sensors. Applied voltage was AC $1 \mathrm{~V}$ and the frequency was $100 \mathrm{~Hz}$. The $\mathrm{RH}$ range of $11-97 \%$ was obtained using saturated salt solutions as the humidity generation sources. The seven different saturated salt solutions were $\mathrm{LiCl}$, $\mathrm{MgCl}_{2}, \mathrm{~K}_{2} \mathrm{CO}_{3}, \mathrm{NaBr}, \mathrm{KCl}, \mathrm{SrCl}_{2}$, and $\mathrm{K}_{2} \mathrm{SO}_{4}$ and their corresponding $\mathrm{RH}$ values were 11, 33, 43, 57, 71,84 , and $97 \% \mathrm{RH}$, respectively. The humidity and temperature were calibrated by humidity temperature digital instrument (HT-3015 type, Lutron, Taiwan).

X-Ray powder Diffraction (XRD) patterns were obtained on a Philips X'PERT MPD diffractometer using $\mathrm{Cu}-\mathrm{K}$ radiation. Scanning Electron Microscopy (SEM) images were observed using a Tescan VEGA device (Czech) after gold-plating of the samples. The nitrogen adsorption and desorption isotherms at $77 \mathrm{~K}$ were measured using a Micromeritics ASAP 2020 instrument.

\section{Results and discussion}

\subsection{Structure and morphology}

The powder X-Ray Diffraction (XRD) patterns (Figure 2) of MCM-48 and Li-MCM-48(X) samples with various $\mathrm{LiCl}$ mass fractions show the most intense 


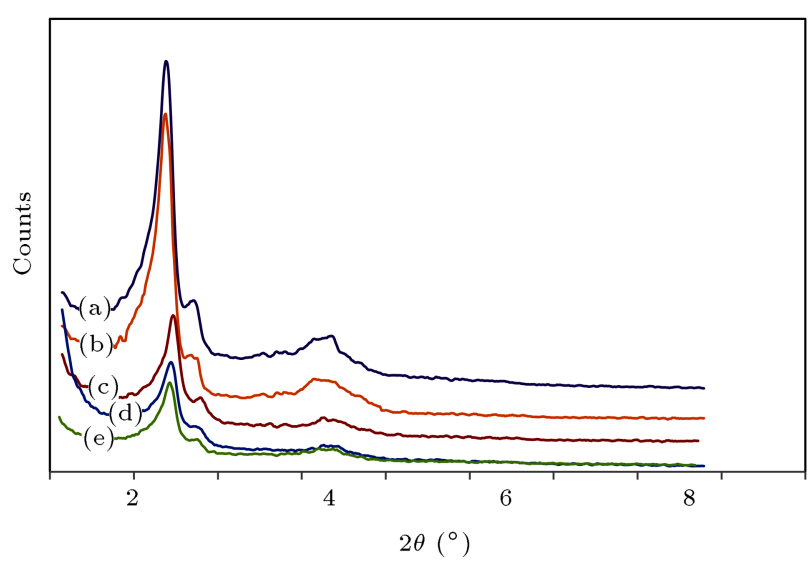

Figure 2. Low-angle XRD spectra of pure MCM-48 (a), LiCl-MCM-48(0.05) (b), LiCl-MCM-48(0.1) (c), LiCl-MCM-48(0.15) (d), and LiCl-MCM-48(0.20) (e).

diffraction peak $(211)$ at $2 \theta=\sim 2.6^{\circ}$ along with a distinct shoulder peak $(220)$ at $2 \theta=\sim 3.0^{\circ}$. Other low intense diffraction peaks of higher order appear at $2 \theta=4^{\circ}-6^{\circ}$, which belong to bicontinuous space group $(I a 3 d)$ of a cubic system. However, the intensity of the reflections decrease after adding $\mathrm{LiCl}$. In Figure 2, the LiCl-doped sample presents a few sharp peaks. With the increase in the content of $\mathrm{LiCl}$, the crystalline feature of $\mathrm{LiCl}$ appears clear. It is reported, earlier, that the doping of $\mathrm{LiCl}$ in the MCM-48 mesoporous material causes a slight decrease in the intensity of XRD patterns [21].

Figure 3 shows FT-IR spectra of the pure MCM48 and LiCl-MCM-48 $(X)$ with $X=0,0.05,0.1,0.15$, and 0.20 . A broad band around $3433 \mathrm{~cm}^{-1}$ is assignable to $\mathrm{OH}$ stretching vibration of $\mathrm{Si}-\mathrm{OH}$ on MCM-48 as well as adsorbed water. The vibration absorption bands at $1235 \mathrm{~cm}^{-1}$ and $1083 \mathrm{~cm}^{-1}$ are due to asymmetric vibration $v_{a s}$ (Si-O-Si) of silica framework. Two more bands at 805 and $458 \mathrm{~cm}^{-1}$ are due to the symmetric

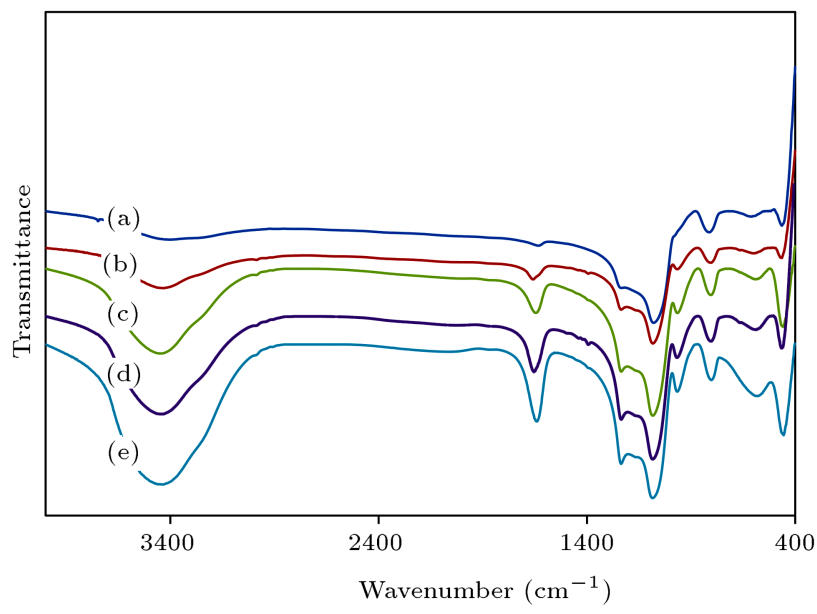

Figure 3. FT-IR spectra of pure MCM-48 (a), LiCl-MCM-48(0.05) (b), LiCl-MCM-48(0.1) (c), LiCl-MCM-48(0.15) (d), and LiCl-MCM-48(0.20) (e).
Table 1. Structural and textual properties of mesoporous silica MCM-48 and LiCl-MCM-48(0.15).

\begin{tabular}{lccc}
\hline \multicolumn{1}{c}{ Sample } & $\begin{array}{c}\text { BET } \\
\text { surface area } \\
\left(\mathbf{m}^{\mathbf{2}} / \mathbf{g}\right)\end{array}$ & $\begin{array}{c}\text { Pore } \\
\text { volume } \\
\left(\mathbf{c m}^{\mathbf{3}} / \mathbf{g}\right)\end{array}$ & $\begin{array}{c}\text { Pore } \\
\text { diameter } \\
(\mathbf{n m})\end{array}$ \\
\hline Pure MCM-48 & 795 & 0.71 & 3.74 \\
LiCl-MCM-48(15) & 611 & 0.54 & 3.46 \\
\hline
\end{tabular}

stretching and bending vibration of rocking mode of Si-O-Si, respectively. Also, it can be observed that the absorption band at about $966 \mathrm{~cm}^{-1}$ was attributed to the Si-O stretching vibration of $\mathrm{Si}-\mathrm{OH}$ in $\mathrm{MCM}-48$ samples.

SEM images of LiCl-MCM-48(0.15) are shown in Figure 4. Consistent with the XRD observation, the sample exhibits a long-range ordered cubic-type pure structure of MCM-48. The doping of $\mathrm{LiCl}$ did not influence the morphology and also did not damage the silica framework of MCM-48. Similar microstructure was observed for all the samples tested in this work.

The $\mathrm{N}_{2}$ adsorption/desorption isotherms and pore size distribution of MCM-48 and LiCl-MCM-48(0.15) are shown in Figure 5. The textural properties of the corresponding samples are given in Table 1. A typical reversible type IV adsorption isotherm was observed for all the mesoporous samples.

The first step in a relative pressure range of 0.18 0.3 is attributed to the nitrogen condensation that took place at the internal mesopores, and the second step above 0.95 in the adsorption branch is due to interparticle voids, which indirectly reflects the size of particles: the higher step shows a small particle size and a relatively smaller surface area and average pore size, which is due to the dispersion of $\mathrm{LiCl}$ in the mesoporous channel.

\subsection{Humidity sensing properties}

Figure 6 shows the impedance and RH characteristics of MCM-48 and LiCl-MCM-48( $X)$ with different amounts of LiCl. Compared to MCM-48, LiCl-MCM$48(X)$ exhibits greatly improved sensitivity. The impedance of the film decreases with the increase in the dopant content in the whole $\mathrm{RH}$ range. Addition of $\mathrm{Li}^{+}$leads to a distinct increase in $\mathrm{RH}$-sensitivity. We think that this is due to the direct participation of the $\mathrm{Li}^{+}$ion in the humidity sensitive conduction. With the increase in the Relative Humidity ( $\mathrm{RH})$, the impedance is decreased. The results suggest that the sample LiCl-MCM-48(0.15) has the best linearity (impedance versus $\mathrm{RH}$ ), and therefore, the following discussions are focused on this sample.

In order to find the optimization relationship between impedance and relative humidity of the $\mathrm{LiCl}$ MCM-48(0.15), we have measured the impedance at different frequencies and the results are shown in 


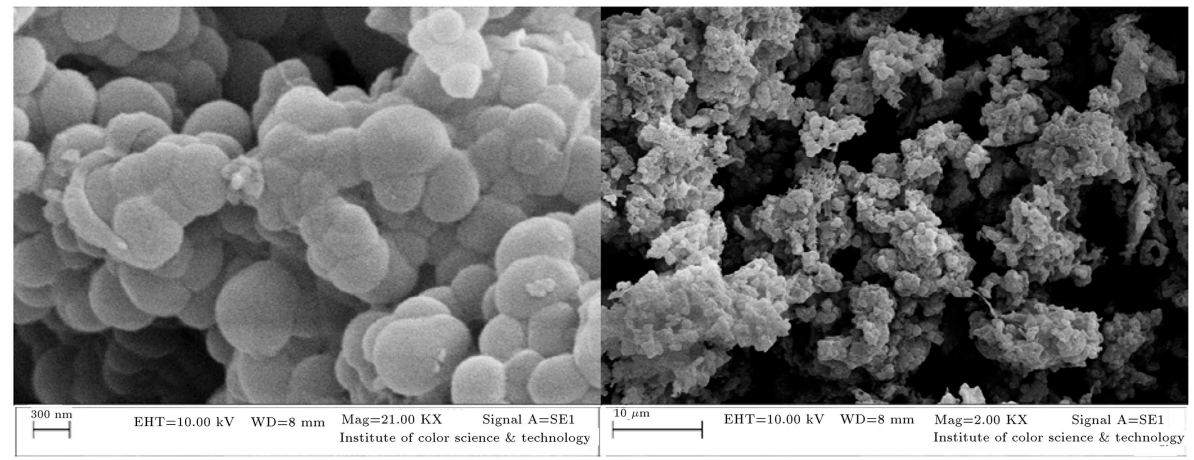

(a)

(b)

Figure 4. SEM images of $15 \mathrm{wt} \%$ LiCl-doped MCM-48: (a) $300 \mathrm{~nm}$; and (b) $10 \mu \mathrm{m}$.

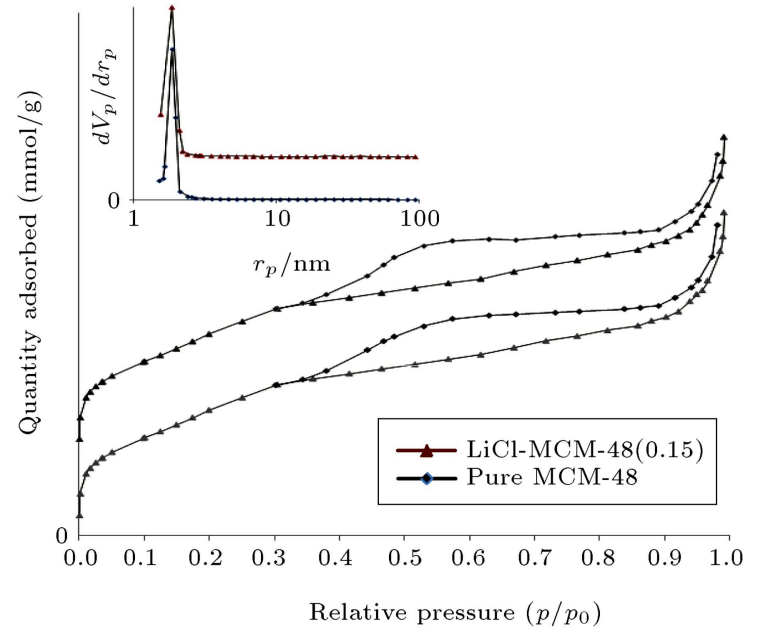

Figure 5. Nitrogen adsorption/desorption isotherms at $77 \mathrm{~K}$ and BJH pore size distributions (inset) determined on the basis of the adsorption branches for pure MCM-48 and LiCl-MCM-48(0.15).

Figure 7. It is clear that at low RH, the frequency influence on the impedance is greater than that at high RH. Therefore, we kept the operation AC voltage and frequency at $1 \mathrm{~V}$ and $100 \mathrm{~Hz}$, respectively, in the following experiments.

The adsorption/desorption $\mathrm{RH}$ hysteresis curves of a LiCl-MCM-48(0.15) sensor are shown in Figure 8. It can be noted that the sensing element exhibits a narrow hysteresis loop during the cyclic humidity operation (11\%-97\% RH). This indicates a good reliability of the obtained sensors.

Figure 9 shows the response and recovery curve of sample LiCl-MCM-48(0.15).

The time taken by the sensor to achieve $90 \%$ of the total impedance change is defined as the response time in the case of adsorption or the recovery time in the case of desorption. The response time (as the humidity changes from $11 \%$ to $97 \% \mathrm{RH}$ ) is $22 \mathrm{sec}$ and the recovery time (as the humidity changes from $97 \%$ to $11 \% \mathrm{RH})$ is $30 \mathrm{sec}$ for the sample LiCl-MCM-48(0.15). To test the stability of LiCl-MCM-48(0.15), the

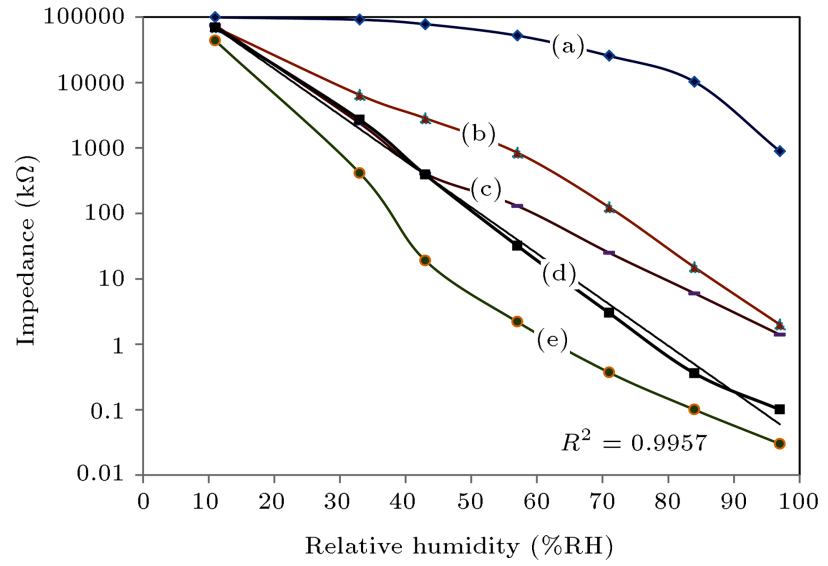

Figure 6. The dependence of resistance on RH for pure MCM-48 (a), LiCl-MCM-48(0.05) (b), LiCl-MCM-48(0.1) (c), LiCl-MCM-48(0.15) (d), and LiCl-MCM-48(0.20) (e) at the frequency of $100 \mathrm{~Hz}$.

sensor was exposed to air for 56 days, followed by measuring impedances at various RHs. As shown in Figure 10, there is acceptable change in the impedances, proving the good stability of LiCl-MCM-48(0.15). It is clear that our product shows good stability and there are no obvious changes in impedance over this period. The long-term stability of the LiCl-MCM-48(0.15) sensor is also shown in Figure 10. The impedances of the LiCl-MCM-48(0.15) sensor with time at different RHs are shown. The measurement was repeated at room temperature every 7 days. Slight variation in impedance was observed over the time period. It can be seen that a nearly constant relationship between signal and humidity exists during the test, indicating that the LiCl-MCM-48(0.15) sensor has prominent stability and is quite promising for a practical application.

\subsection{Sensing mechanism}

The fundamental mechanism that enables ceramic sensors to sense humidity is related to the adsorption of water molecules on the film surface with large surface area. At low relative humidity, only few water molecules are adsorbed by chemisorption mechanism 


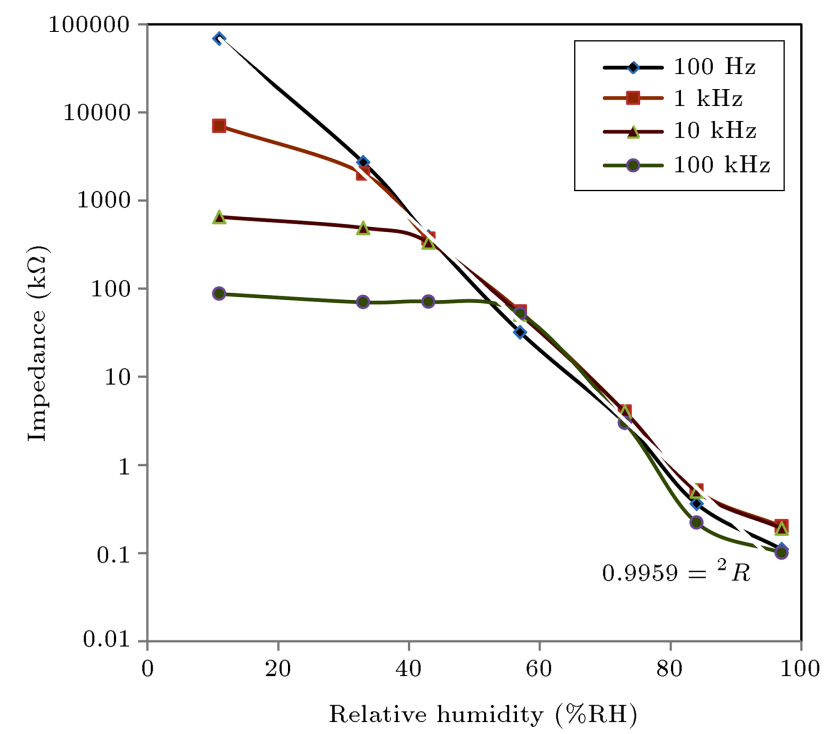

Figure 7. Relationship between impedance and RH at different frequencies based on LiCl-MCM-48(0.15).

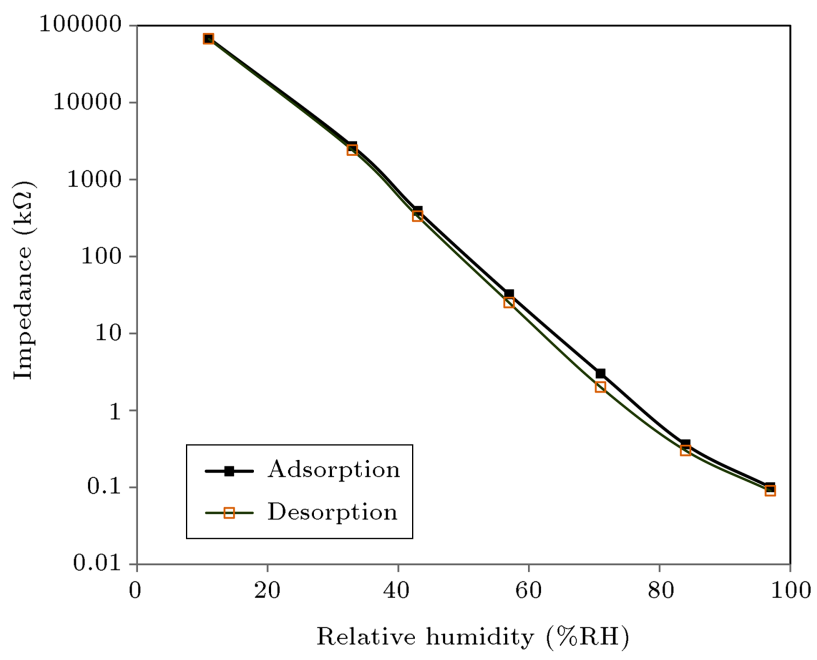

Figure 8. Hysteresis of LiCl-MCM-48(0.15) sensor measured at $100 \mathrm{~Hz}$.

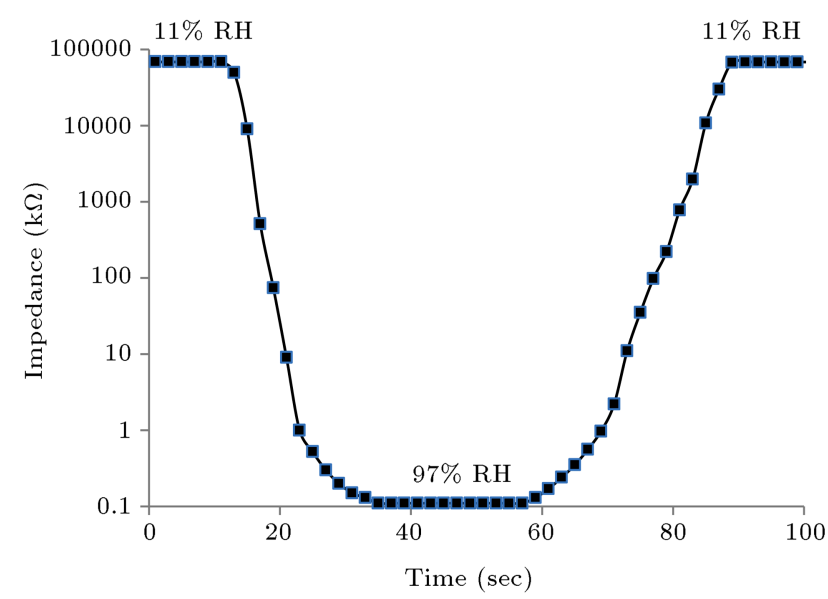

Figure 9. Response and recovery properties of the humidity sensor.

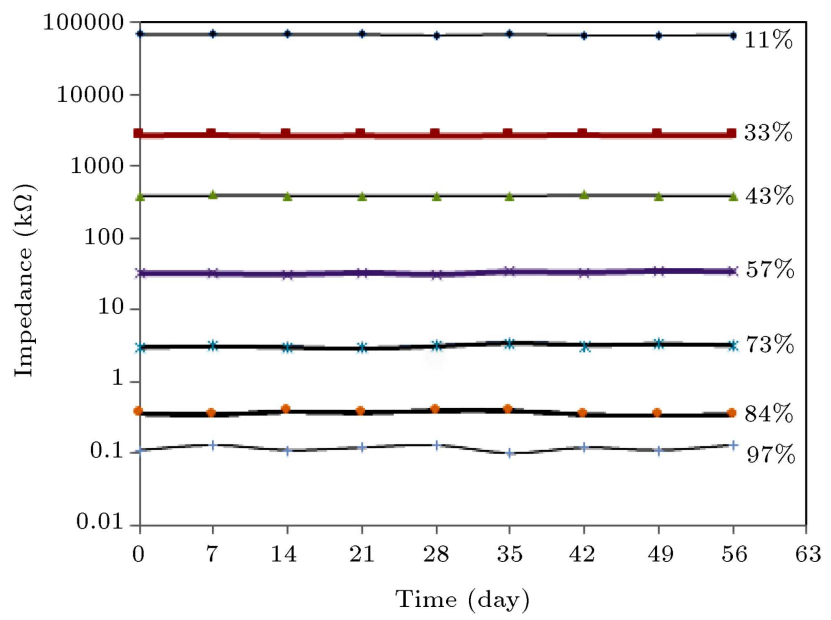

Figure 10. Stability of the LiCl-MCM-48(0.15) sensor measured at $100 \mathrm{~Hz}$.

according to Kulwicki [22], and reduction in impedance is due to proton hopping between hydroxyl ions on this layer. But, due to the adsorption of few water molecules, this layer is not continuous. Thin film exhibits higher impedance at low relative humidity. With increasing humidity levels, water is physisorbed on top of the chemisorbed layer and protons hop between physisorbed molecules in the continuous water layers, with a charge transport by a Grotthuss mechanism [23]. The presence of two interpenetrating continuous networks of chiral channels in MCM-48 permits the condensation of physisorbed water, resulting in electrolytic conduction, which is added to protonic conduction of physisorbed layers. So, the impedance is further decreased by the presence of pores on the sample surface [24-26]. The LiCl-doped nanoporous MCM-48 thin film has nanosized grains and nanopores and these nanopores lead to more active sites available for condensed water to react. This succession of mechanisms leads to a rapid decrease in impedance with increasing $\mathrm{RH}$.

\section{Conclusions}

MCM-48 and its blends with $\mathrm{LiCl}$ were synthesized successfully. Its structure was characterized by X-ray diffraction, IR spectroscopy, $\mathrm{N}_{2}$ adsorption/desorption, and SEM. The results obtained show that MCM-48, alone, has poor sensitivity to humidity, but the addition of $\mathrm{LiCl}$ enhances the humidity sensitive property of MCM-48. In addition, the results show that the sample LiCi-MCM-48(0.15) has excellent linearity between impedance and humidity in the whole humidity range from $11 \%$ to $97 \%$. The humidity hysteresis loop was narrow, and the response and recovery time was shorter than $30 \mathrm{sec}$. The LiCl-MCM-48(0.15) material has very promising prospects in the field of humidity sensor. 


\section{References}

1. Prasad, G., Prabha, D.I. and Rao, M.V. "Handheld measuring device for multiple parameters, in wood and ceramic industries", IJESAT, 2, pp. 1416-1419 (2012).

2. Zhang, W., Wang, R., Zhang, Q. and Li, J. "Humidity sensitive properties of K-doped mesoporous silica SBA15", Journal of Physics and Chemistry of Solids, 73, pp. 517-522 (2012).

3. Chen, Z. and Lu, C. "Humidity sensors: A review of materials and mechanisms", Sensor Letters, 3, pp. 274295 (2005).

4. Zhang, T., Wang, R., Geng, W., Li, X., Qi, Q., He, Y. and Wang, S. "Study on humidity sensing properties based on composite materials of Li-doped mesoporous silica A-SBA-15", Sensors and Actuators B, 128, pp. 482-487 (2008).

5. Li, Z.Y., Zhang, H.N., Zheng, W., Wang, W., Huang, H.M., Wang, C., MacDiarmid, A.G. and Wei, Y. "Highly sensitive and stable humidity nanosensor based on $\mathrm{LiCl}$ doped $\mathrm{TiO}_{2}$ electro-spun nanofibers", Journal of the American Chemical Society, 130, pp. 5036-5037 (2008).

6. Aoki, H., Azuma, Y., Asaka, T., Higuchi, M., Asaga, K. and Katayama, K. "Improvement of response characteristics of $\mathrm{TiO}_{2}$ humidity sensors by simultaneous addition of $\mathrm{Li}_{2} \mathrm{O}$ and $\mathrm{V}_{2} \mathrm{O}_{5}$ ", Ceramics International, 34, pp. 819-822 (2008).

7. Qi, Q., Feng, Y., Zhang, T., Zheng, X. and Lu, G. "Influence of crystallographic structure on the humidity sensing properties of KCl-doped $\mathrm{TiO}_{2}$ nanofibers", Sensors and Actuators B: Chemical, 139(2), pp. 611617 (2009).

8. Zhao, D. and Goldfarb, D. "Synthesis of manganese containing mesoporous molecular sieve Mn-MCM41, Mn-MCM-48 and Mn-MCM-L", Journal of the Chemical Society, Chemistry Community, pp. 875-876 (1995).

9. Froba, M., Kohn, R., Bouffaud, G., Richard, O. and Van, G. " $\mathrm{Fe}_{2} \mathrm{O}_{3}$ nanoparticles within mesoporous MCM-48 silica: in situ formation and characterization", Chemistry of Materials, 11, pp. 2858-2865 (1999).

10. Moller, K., Bein, T. and Fischer, R.X. "Entrapment of PMMA polymer strands in micro- and mesoporous materials", Chemistry of Materials, 10, pp. 1841-1852 (1998).

11. Joo, S.H., Jun, S. and Ryoo, R. "Synthesis of ordered mesoporous carbon mulecular sieves CMK-1", Microporous Mesoporous Materials, 44, pp. 153-158 (2001).

12. Melde, B.J., Johnson, B.J. and Charles, P.T. "Mesoporous silicate materials in sensing", Sensors, 8, pp. 5202-5228 (2008).

13. Kresge, C.T., Leonowicz, M.E., Roth, W.J., Vartuli, J.C. and Beck, J.S. "Ordered mesoporous molecular sieves synthesized by a liquid-crystal template mechanism", Nature, 359, pp. 710-712 (1992).
14. Beck, J.S., Vartuli, J.C., Roth, W.J., Leonowicz, M.E., Kresge, C.T., Schmitt, K.D., Chu, C.T.W., Olson, D.H., Sheppard, E.W., McCullen, S.B., Higgins, J.B. and Schlenker, J.L. "A new family of mesoporous molecular sieves prepared with liquid crystal templates", Journal of the American Chemical Society, 114, pp. 10834-10836 (1992).

15. Monnier, A., Schuth, F., Huo, Q., Kumar, D., Margolese, D., Maxwell, R.S., Stucky, G.D., Krishnamurty, M., Petroff, P., Firouzi, A., Janicke, M. and Chmelka, B.F. "Cooperative formation of inorganic-organic interfaces in the synthesis of silicate mesostructures", Science, 261, pp. 1299-1300 (1993).

16. Kim, T.W., Kleitz, F., Paul, B. and Ryoo, R. "MCM48-like large mesoporous silicas with tailored pore structure: facile synthesis domain in a ternary triblock copolymer-butanol-water system", Journal of the American Chemical Society, 127, pp. 7601-7605 (2005).

17. Wu, M., Sun, H. and Li, P. "CuO-doped $\mathrm{ZnCr}_{2} \mathrm{O}-$ 4-LiZnVO 4 thick-film humidity sensor", Sensors and Actuators B, 17, pp. 109-110 (1994).

18. Geng, W., Wang, R., Li, X., Zou, Y., Zhang, T., Tu, J., He, Y. and Li, N. "Humidity sensitive property of Li-doped mesoporous silica SBA-15", Sensors and Actuators B, 127, pp. 323-329 (2007).

19. Zhang, T., Wang, R., Geng, W., Li, X., Qi, Q., He, Y. and Wang, S. "Study on humidity sensing properties based on composite materials of Li-doped mesoporous silica A-SBA-15", Sensors and Actuators B, 128, pp. 482-487 (2008).

20. Atmanand, M.A. and Jagadeesh Kumar, V. "Microcontroller based LCR meter", Microprocessors and Microsystems, 20, pp. 297-301 (1996).

21. Chino, N., Ogura, M., Kodaira, T., Izumi, J. and Okubo, T. "Characterization of ESR active species on lithium chloride-modified mesoporous silica", Journal of Physics and Chemistry of Solids, 109, pp. 8574-8579 (2005).

22. Kulwicki, B.M. "Humidity sensors", Journal of the American Chemical Society, 74, pp. 697-708 (1991).

23. Ernsberger, F.M. "The nonconformistion", Journal of the American Chemical Society, 66, pp. 747-750 (1983).

24. Traversa, E., Bearzotti, A., Miyayama, M. and Yanagida, H. "Study of the conduction mechanism of heterocontacts at different relative humidities", Sensors and Actuators B, 25, pp. 714-718 (1995).

25. Anbia, M. and Moosavi Fard, S.E. "Improving humidity sensing properties of nanoporous $\mathrm{TiO}_{2}-10 \% \mathrm{SnO}_{2}$ thin film by co-doping with $\mathrm{La}^{3+}$ and $\mathrm{K}^{+}$", Sensors and Actuators B, 160, pp. 220-223 (2011).

26. Anbia, M. and Moosavi Fard, S.E. "Humidity sensing properties of Ce-doped nanoporous $\mathrm{ZnO}$ thin film prepared by sol-gel method", Journal of Rare Earths, 30, pp. 40-41 (2012). 


\section{Biographies}

Mansoor Anbia obtained his MSc degree from Tarbiat Moallem University, Tehran, doing a case study on "Synthesis, properties, and applications of lanthanum silicates as mineral ion-exchangers". Then, he did a Post MSc research on "Measuring 222Rn content of mineral water employing alpha-spectroscopy and liquid scintillation method" at the same University. He also received his $\mathrm{PhD}$ degree from Tarbiat Moallem University, Tehran, in 2007 under the supervision of Professor Vaghef Hossein. His thesis was entitled "Case study on synthesis, properties and analytical applications of novel mesoporous compounds of lanthanum silicate, lanthanum phosphate, lanthanum tantalate and titanium phosphate".

Dr. Anbia has been honored with several national and international scientific awards. He is currently an Associate Professor at Iran University of Science and Technology and, at the same time, the President of the Chemistry and Chemical Engineering Research Center of Iran. His research interests include inorganic ion-exchangers, mesoporous adsorbents, nano-structure new materials, chromatography (HTPLC, HPLC \& GSC), removal of organic and inorganic pollutants from industrial effluents, purification methods for recovery of different chemical compounds from industrial waste, and application of new materials for using in different industrial plants.

Saeid Kadkhodazade obtained his MSc degree from Chemistry and Chemical Engineering Research Center of Iran. After successfully passing the national examination, he carried out his MSc thesis project under the supervision of Dr. Mansoor Anbia, focusing on humidity sensing properties of various nanoporous materials. 